\title{
MULTIMODAL DISCOURSE ANALYSIS OF TOURISM WEBSITES - THE PROMOTION OF CULTURAL VALUES THROUGH THE LANGUAGE OF TOURISM
}

\begin{abstract}
In this article, the elements of promotional tourism campaigns of three countries aimed at English-speaking tourists are analyzed including their English slogans, short films in English featured on their official tourism websites and English texts in the About sections of the websites. For this purpose, multimodal discourse analysis and corpus analysis have been used. The main objective has been to identify specific cultural values and markers that have been chosen for presentation to tourists. The results have shown that each country adopted a rather different approach to create a unique, recognizable image for international tourists. Finally, an overview of pedagogical implications has been presented regarding ESP teaching within tertiary and professional education in the field of tourism and hospitality.
\end{abstract}

Key words: corpus analysis, English for Tourism, multimodal discourse analysis, tourism websites

\section{Introduction}

According to Thurlow and Jaworski (2011: 286), "language scholars and academics working in the interdisciplinary field of critical tourism studies have often had to justify their scholarly interests to those unable to see beyond their own personal experience of tourism as a frivolous and recreational activity." Today tourism is a global industry, so even the most remote areas of our planet are affected by tourism. The anthropologist Edward Bruner (2005: 10) explained earlier that tourism is simply "one of the greatest population movements of all time." Since the 1970s, tourism discourse has become the focus of interdisciplinary analysis, which encompasses the interaction of the tourism domain, discourse and communication while creating opportunities to study interpersonal and intergroup relations alongside with international and intercultural relations and contacts (Jaworski and Pritchard 2005). In

\footnotetext{
* Department of Geography, Tourism and Hotel Management, Faculty of Sciences, University of Novi Sad, Trg Dositeja Obradovića 3, 21000 Novi Sad, Serbia; e-mail: vukovic.vojnovic@gmail.com
} 
terms of sociolinguistics, the language of tourism can be perceived as the language of a specific profession or a group of people and can be studied as a specific subtype of languages for specific purposes spoken by natives or non-natives.

Tourism is a broad term and it can be defined differently depending on the context, and the audience. The most common definition is given by the United Nations World Tourism Organization defining tourism as the 'activities of persons travelling to and staying in places outside their usual environment for not more than one consecutive year for leisure, business and other purposes not related to the exercise of an activity remunerated (i.e. without receiving a salary/wage for said activity/activities) from within the place visited.'

In the context of this paper, tourism is viewed as a profession which entails specific types of discourse with a variety of contexts, actors and purposes. Without going into further genre analysis recognized and proposed by Swales and Bhatia (Swales 1990; Bhatia 1993; Bhatia 2002), we will acknowledge that the analysis of tourism discourse is situated at the crossroads between tourism as an academic field and tourism as a subject of discourse analysis. More specifically, multimodal communication in the field of tourism can be seen as a specialised discourse since it has a set of specific communicative events and cultural and social purposes recognized by the members of a specific professional and academic community, including specific lexis and moves. Finally, within the framework of the tourism sector, English as a foreign or second language is studied as a global means of communication in tourism and hospitality.

\section{Research aims}

This article aims to first briefly present theoretical background behind the study of nature and unique properties of English for Tourism, more specifically its vocabulary. Secondly, by implementing a multimodal approach and corpus analysis, three case studies of tourism websites have been observed in order to see how different communicative modes are used in presenting cultural values of three different countries. More specifically, communicative purposes and means have been explored in short promotional video materials alongside with accompanying slogans and logos. In addition, the English texts in the introductory sections of the websites have been analysed by identifying keywords and terminology in order to establish the main communicative purposes of the written part of the websites and compare them with those promoted in the visual material. Finally, we have tried to highlight pedagogical implications for teaching English for Tourism to non-linguistic professionals and

\footnotetext{
${ }^{1}$ http://www2.unwto.org/
} 
students who need to understand the preferred ways of communication within hospitality and tourism sectors. In this way, ESP teachers would be able to provide their students with deeper insights into real life situations and the ways language is actually used in these instances. Moreover, the main goal of this article is to use the findings for designing tailor-made materials to be used for English classes for the students of tourism and hospitality at the university level and in professional training.

\section{Theoretical framework for studying the language of tourism}

Since the language of tourism promotion has been more in the focus of research studies conducted by marketing, management, sociolinguistics and semiotics specialists, and less in the focus of applied linguistics research, the overview of theory needs to cover the literature in these fields as well. In this section of the article, we look into the theory behind some of the key strategic markers that are expected in promotional tourism campaigns, usually including the elements of authenticity, cultural and social identity of a destination, novelty experience, and elements of play or adventure, as well as mythical or magical elements.

For Brown and Yule (1983) language and communication are two-dimensional, both possessing a transactional and interactional aspect. The first refers to the coherent and precise transmission of information and the second deals with social interaction and relationships in communication. Regarding tourism websites, in addition to simply providing information and services in a transactional manner, their main aim is to establish a bond (the interactional dimension) between the message sender (i.e. travel agents or tour operators) and the message receiver (i.e. clients, tourists or travellers) by means of multimodal devices. In the context of this interactional bond, the sender will explicitly attempt to evoke positive emotion in the receiver with the objective of attracting tourists and creating an inherent desire to visit a particular destination.

In the same manner that an original advertising campaign is associated with a new innovative product, a strong communication strategy is vital for success in the professional setting of the tourism industry. For the field of tourism, communication strategy is often based on the three stages of a trip or voyage (Bruner 2005; Bruner 2005a) - the imagined journey when tourists are exploring their options for travelling (pre-tour marketing), the actual voyage when they interact with the location and the people (the trip itself), and the extended journey when tourists recount their travel experience (post-tour narratives). In this article, we have been interested in the first stage of a trip, and more specifically in the way the language was used to communicate certain values to prospective tourists who are imagining their dream holiday experience in a trustworthy holiday destination. In this context, promotional materials such as 
brochures, videos, advertising campaigns, television commercials, guidebooks, websites, and social network pages have to be designed with the right cultural image in mind and the right verbal and non-verbal means that would be appealing to prospective tourists.

Specific semiotic codes and symbols attract certain tourists to precise places for a particular experience. One of the powerful semiotic operators within the tourism sector is the distinction between authenticity and inauthenticity. Culler (1990) states that authenticity has always been a powerful promotional tool in the field of tourism. In promotional materials, powerful images of tourist destinations are often surrounded by adjectives such as: actual, original, authentic, real or true. The evidence of this principle can be found in the promotional slogans of national tourism organizations, such as: Malaysia Truly Asia, 100\% Pure New Zealand or Jamaica: Once you Go You Know! Another distinctive quality found in the language of tourism is the idea of novelty, which has been known as one of the basic drivers of tourist movement (Dann 1996). Destination descriptions in promotional brochures or multimedia aim to portray the image of something that is unique, strange, and extraordinary. This heightens the curiosity level of tourists prior to their arrival and raises their expectations. Some examples of campaign slogans that promote such features are: California Find yourself here! There's nothing like Australia! Incredible!ndia ${ }^{2}$, or A Touch of Exotic - Dumfries and Galloway, Scotland. In addition, the elements of play, adventure and total relaxation are extremely important in tourism. This dimension is often presented through various forms of animations and activities, which provide tourists with the opportunity to actively participate in the events or entertainment. This component of play is reflected in slogans such as Fiji Me!, Romania - Explore the Carpathian Garden, Canada...Keep Exploring!, or Austria-Arrive and Revive! And finally, one last group of important markers which are characteristic of the language of tourism are elements that denote magic, myth, mystery or fantasy. Intriguing and unusual stories that lie behind some tourist attractions are there to create a veil of mystery and leave the rest to the visitors' imagination. For example, the following slogans lure tourists to discover the unknown: Magical Kenya, Zimbabwe - A World of Wonders.

Temporal references are also of interest for the language of tourism since it often neglects the present which may symbolize reality and routine (Dann 1996). If it makes references to the past, it is to promote the tradition, whereas the future references lure tourists to dream about their ideal holiday. In tourism promotion, the language is sometimes used to blur past, present and future by creating a feeling of everlasting, universal experience. This is visible in the minimalist slogans, such as Greece. All Time Classic.

\footnotetext{
${ }^{2}$ !ndia (India)
} 
In more recent applied linguistics research, the interest has shifted from the textual analysis of tourist brochures or websites to a multimodal discourse analysis, taking into account all the visual and audio elements which accompany the texts presented on the websites. Kress (1997: 66) recognises that information previously encoded in language is now presented visually, in the new digital age. In his later work, Kress (2010) claims that all communication is multimodal, since there is always an interplay of different modes of communication (e.g. written text, image, sound, animations, films, etc). Additionally, such an understanding of communication affects the language teaching process. In other words, as new communication strategies are influenced by new technologies, it is important to consider the ways of integrating multimodal aspects of presenting information into language teaching materials.

\section{Multimodal approach as research methodology}

As Pauwels (2012: 247) mentions, studying websites as cultural phenomena has been a focus of interest for many scholars since the late nineties, although the methods they applied were mainly orientated towards verbal means of communication. Today the focus has shifted towards the numerous visual and multimedia features of the websites to be investigated along with the verbal elements. New approaches to discourse analysis claim that all discourse is multimodal and not monomodal (Scollon and LeVine 2004: 3).

Multimodality as a framework for analysis is actually an analysis of the modes of communication through speech, colour, taste, the design of images (Van Leeuwen 2004) in addition to the textual analysis, and it is important, according to Van Leeuwen (2004: 8), for linguists to start considering visual communication as equally important as textual. We have to agree with this author, especially because our interest lies in the analysis of the language of tourism which has always been replete with images and visual communication, even in the pre-Internet era - in tourism brochures, posters, postcard, leaflets and similar media of communication. More generally, it could be claimed that all communication is multimodal and includes both verbal and non-verbal elements. Van Leeuwen (2004: 8) proposes that speech acts should be renamed communicative acts to comprise all the multimodal micro-events which are combined into a communicative intent. Multimodal approach to communication allows us to see a promotional poster not as a combination of two speech acts - one verbal and one visual, but as a single multimodal communicative act (Van Leeuwen 2004: 7). In the new technology era, which produced new media of communication, it is important to combine the analysis of writing or speech with other semiotic modes (Van Leeuwen 2004: 11). Even the textual part should be considered as a multimodal act if particular typography is applied, so the text is no longer a purely linguistic feature as a specific semiotic mode (Van Leeuwen 
2004: 14). Some specific types of font can provide more readability for younger readers, for example, or give emphasis to a particular textual message, wordplay, symbol, etc. In the language of tourism promotion this can be found in logos or slogans, as it will be shown later in the section where research findings are presented.

In pursuit of terminological clarity, some scholars try to distinguish between the modes of 'multimodality' or the technology of representation and the media of multimediality or the technologies of dissemination (Jewitt 2004: 184). As the author explains, this means that the message receiver is in interaction both with the modes and media of communication when interpreting the information they need. If we apply this to searching through a promotional tourism website, the user would read the text, search through visual and audiovisual material, and also select the visual hyperlinks that would take them to another virtual place where they can get further information, watch a video, etc. In this type of analysis, it is interesting to explore whether the visual modal resources (e.g. images, video clips) and written resources are used differently (Jewitt 2004: 187), i.e. for different communicative purposes. This is similar to what Kress (2010) calls intersemiotic relationship, which is the connection and the construction of meaning among different semiotic modes.

Another topic of interest worth mentioning, within multimodality framework, would be studying the effects of new technologies on communication explored by Scollon and LeVine (2004: 3).They recognized the role that World Wide Web had on discourse analysis by opening ways to new social interactions (Scollon and LeVine 2004: 3-4). Although this is an extremely interesting topic for investigation, it goes beyond the scope of this article and will not be addressed further.

\section{Research design}

After establishing a theoretical background for the study of the nature and unique properties of the language of tourism, we proceeded with a partial multimodal analysis of promotional tourism campaigns for the English-speaking tourists of three different countries with a shared history and culture, namely North Macedonia, Serbia and Slovenia. It is important to acknowledge that the nature of the promotional activities of national tourism organisations is to create a positive, attractive public image of their respective countries, especially having foreign tourists and visitors in mind. Overall, for research of the visual semiotic modes, mainly video clips and images, the method of keyword associations was used, and for the linguistic mode (i.e. texts) corpus analysis was applied along with the multimodal analysis.

Firstly, in order to identify which public image and cultural and/or social values were chosen to be promoted for each country, spatial, visual and linguistic modes used to create logos and slogans were analyzed. Furthermore, we paired this part of the 
analysis with the identification of keywords, multi-word terms and key concepts that can be associated with the additional visual representations - i.e. short promotional video clips. Tourism campaigns of each country featured several longer and shorter versions of video clips aimed at various tourist markets. For the purpose of this article, we chose one short video clip without narration aimed at English-speaking tourists for each country. Finally, for the linguistic part, we opted for the corpus analysis of short texts written in English and collected from the introductory sections or general information sections of the observed websites excluding the links to external websites, if any. We will refer to these texts as the Macedonian Corpus (MC), Serbian Corpus (SRC) and Slovenian Corpus (SLC) for clarity, although the actual texts were all written in English. The main objective was to look for keywords and multi-word terms which would be specific to the analysed corpora. Each corpus was analysed by Sketch Engine ${ }^{3}$, an online tool for data mining and text analysis, which calculates word frequencies with tools already incorporated in its $\mathrm{API}^{4}$, and provides keyness score which shows how specific the term is for the analyzed corpus. Higher scores mean that the multi-word terms are more specifically related to the content and the context of the specialized corpus. When the texts are uploaded for analysis, they are fully automatically processed into a corpus, including part-of-speech tagging and lemmatization. Finally, we chose the top multi-word terms that appeared three or more times in the analysed corpora for the topic modelling of each text, i.e. to determine the main topics and concepts presented in the texts. The main research interests of this article can be summarized into the following questions:

- Which representations of the public image and cultural values were promoted? In other words, did campaigns promote more cultural, historical, geographical or other elements that can contribute to the public image and promotion of a country?

- How were these concepts promoted through various modes - visual, linguistic, spatial?

- Did short videos, logos and slogans incorporate the concepts promoted in the introductory texts?

- What are the intersemiotic relations between the textual and the visual part?

- What are the differences and similarities across the three tourism websites?

\section{Research results and discussion}

It is evident in the Table 1 (below) that the three corpora were not the same in size, which is not relevant for this analysis because we were not interested in the absolute

\footnotetext{
${ }^{3}<$ https://www.sketchengine.eu/\#blue $>$

${ }^{4}$ Application Programming Interface
} 
and relative frequencies of the keywords and multi-word terms, but we needed them for establishing the overall topic and conceptual nature of each website. The number of tokens refers to the number of words regardless of their repetition in the text.

\begin{tabular}{|c|c|c|}
\hline WEBSITE & CORPUS SOURCE & CORPUS SIZE \\
\hline https://macedonia-timeless.com/ & About section & $\begin{array}{c}\text { tokens: } 14,085 \\
\text { words: } 12,193 \\
\text { sentences: } 591\end{array}$ \\
\hline http:/www.serbia.travel/home.779.html & About (Serbia) section & $\begin{array}{c}\text { tokens: } 8,992 \\
\text { words: } 7,172 \\
\text { sentences: } 214\end{array}$ \\
\hline https://www.slovenia.info/en & Plan your trip section & $\begin{array}{c}\text { tokens: } 12,558 \\
\text { words: } 10,794 \\
\text { sentences: } 527\end{array}$ \\
\hline
\end{tabular}

Table 1. Corpora details

As we can see from Table 1 (above), the largest corpus was collected from the North Macedonia tourism website. This site, along with the Serbian website, included the About section as one of its main segments, with several internal links, whereas the Slovenia tourism website did not have this section, so Plan your trip section with several internal links was analysed instead, as the most general part of the website.

If we look at different modes of communication used in each website, we can spot certain similarities in the organisation of visual and spatial modes. Snapshots of the Slovene website will be analysed in detail as an example of these similarities.

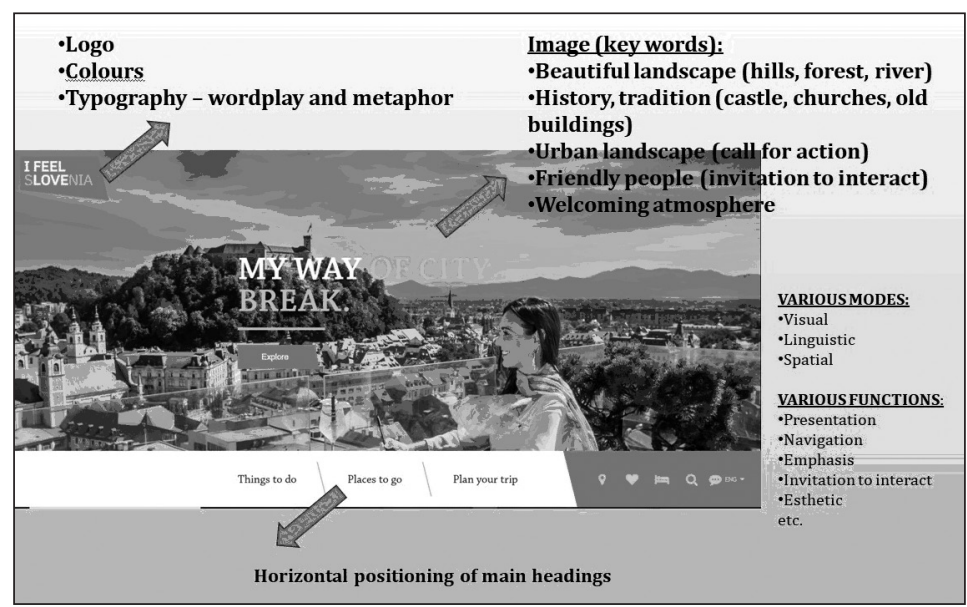

Image 1. Slovenia's tourism website, homepage 


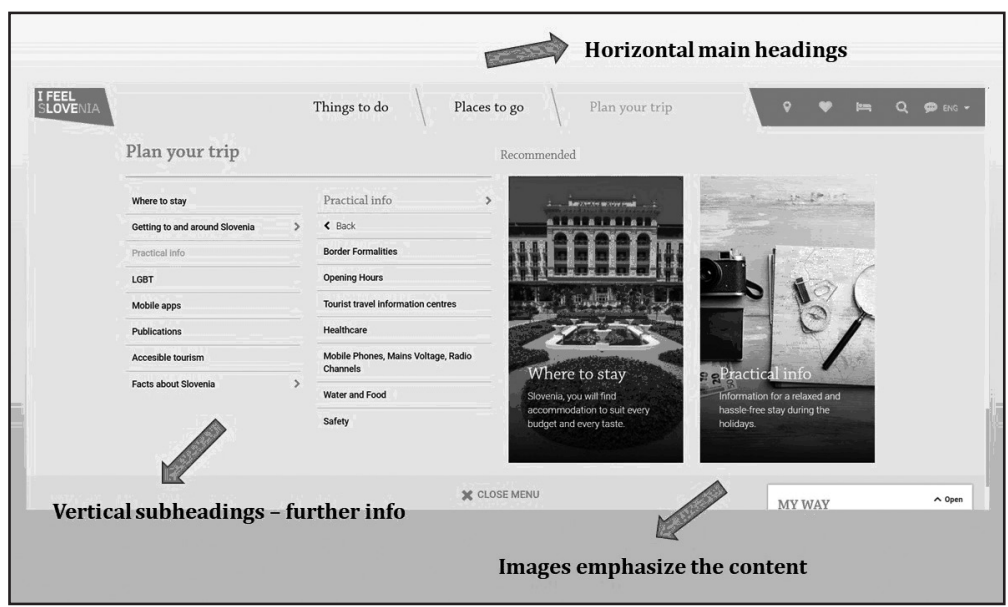

Image 2. Slovenia's tourism website - Plan your trip internal link

First, the spatial modes of communication typically used in tourism organisation website will be discussed. It is evident from Images 1 and 2 (above) that the central place of the website is taken by a photograph. It has a link Explore in the centre of the photograph that calls for interaction with the website visitor and an inspirational quote to tickle the imagination of prospective tourists. The logo and the main slogan are positioned in the upper left corner. The headings of the main sections of the website are positioned horizontally as internal links. There are also some symbols that lead to external links. If we click to the main horizontal links, e.g. Plan your trip link, another menu opens with vertically positioned internal links containing texts that offer more detailed information about the topics. This is all accompanied with the photos which emphasize the topic of each link, e.g. a hotel for the accommodation link called Where to stay, or travel accessories for Plan your trip section (Image 2, above). The links are positioned and designed to ease navigation, emphasize key information and initiate further interaction with the website visitor. The central image can be further analysed by associating keywords with the image, for example: beautiful landscape, history and tradition, urban landscape, friendly people, welcoming atmosphere (Image 1, above). The image aims at comprising everything Slovenia has to offer to different types of travellers - nature lovers, visitors interested in historic places, those looking for interaction and socialising, etc.

The visual and linguistic modes will be analysed further in the separate subsections for each website and corpus. 


\subsection{Keywords, terms and concepts in the Slovene website}

The logo of Slovenia's tourism campaign also incorporates its slogan with a unique word play which is emphasized by specific typography with green and white letters. The slogan is I Feel Slovenia, which is also a metaphor since both the word for the country Slovenia and the word for the nation the Slovenes contain and focus on the word love which is in the middle. So, we can read the slogan I Feel Slovenia as I Feel Love. In our opinion, the colours white and green evoke the colours of Slovenia's numerous mountains and forests in all four seasons.

There are copious video materials produced for this campaign, but we chose a one-minute short video entitled Invitation to Slovenia: Feel Slovenia which features Slovenia's famous tourist attractions and locations, accompanied by music and names of the places with the logo and slogan at the end of the video. This is a visual story showing the main cultural and natural landmarks of the country, also featuring people in various outdoor activities, enjoying nature, leading a healthy and active life, which is typically associated with the Slovenes.

On the subject of the corpus analysis, there were 623 multi-word terms extracted by the Sketch Engine, with 543 occurring only once in the authentic corpus but never occurring in the general referential corpus. Typical examples of these multi-term words from the corpus are Slovenian camper, Slovenian tourist attraction, exquisite Slovenian food, mysterious karst, or more general combinations that would be expected in the general corpus such as exceptional attraction, local tourist offer, castle park, inspiring green park, daily railway, etc. It should be noted that a detailed analysis of the obtained corpus is beyond the scope of this article, which would require the removal of certain inadequate combinations which are either incorrect or unlikely to be accepted by native speakers, such as !planina plateau, !van rest stop or !multi-day rest. Instead, we looked at the first 18 multi-word terms which appeared three or more times in the Slovenian Corpus. These word combinations are illustrative of the main topics of the texts in the Plan your trip section.

\begin{tabular}{|l|c|c|c|}
\hline Multi-word term & Score & Freq & Ref_freq \\
\hline accessible tourism & 556.19 & 7 & 1 \\
\hline green nature & 394.42 & 5 & 3 \\
\hline consular mission & 318.25 & 4 & 1 \\
\hline small tourist & 312.95 & 4 & 5 \\
\hline german language & 242.25 & 4 & 76 \\
\hline natural health & 199.58 & 4 & 143 \\
\hline railway station & 157.71 & 4 & 244 \\
\hline
\end{tabular}


MULTIMODAL DISCOURSE ANALYSIS OF TOURISM WEBSITES

\begin{tabular}{|l|c|c|c|}
\hline karstic area & 239.89 & 3 & 0 \\
\hline slovenian coast & 239.89 & 3 & 0 \\
\hline ecological manner & 239.89 & 3 & 0 \\
\hline slovenian capital & 238.94 & 3 & 1 \\
\hline slovenian language & 237.99 & 3 & 2 \\
\hline camper van & 229.34 & 3 & 11 \\
\hline safe country & 226.74 & 3 & 14 \\
\hline lesbian community & 203.3 & 3 & 43 \\
\hline tree house & 176.26 & 3 & 86 \\
\hline motor home & 173.58 & 3 & 91 \\
\hline direct contact & 106.24 & 3 & 299 \\
\hline drinking water & 30.79 & 3 & 1614 \\
\hline
\end{tabular}

Table 2. Slovenian Corpus - multi-word terms that appeared three or more times

In the Table 2 (above) the scores are calculated by the so-called simple math method for identifying keywords and terms by the Sketch Engine. Higher keyness scores mean that a particular term is specific for the particular corpus. The second column refers to the actual frequency in the specialised corpus, in this case Slovenian Corpus, and the third column refers to the term frequency in the general reference corpus. When using online or electronic corpus analysis tools, it is important to go through the list and apply one's own judgement, especially when dealing with bigrams, since not all offered combinations are real collocations. For example, multi-word term small tourist that appeared five times in the Slovenian corpus, as it can be seen in Table 2 (above), seems incorrect. However, when its concordance was explored (Image 3, below), it was obvious that it is actually a part of the longer collocation small tourist $\operatorname{train}(s)$.

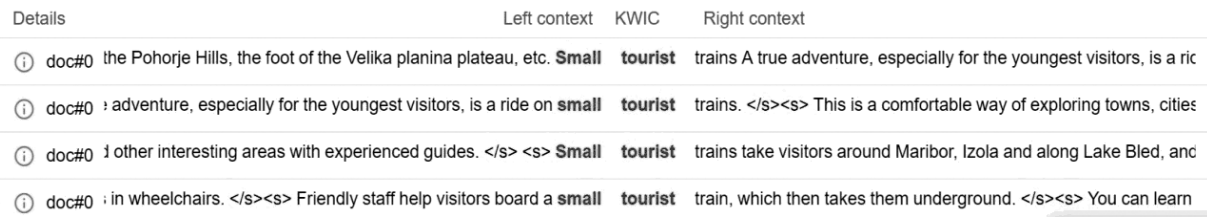

Image 3. Slovenian corpus - small tourist train concordance

After going through all the examples in the list of 18 most frequent multi-word terms in the Slovenian Corpus, they were grouped according to the topic they mostly contributed to. 
Dragana Vuković Vojnović

\begin{tabular}{|c|c|c|}
\hline $\begin{array}{c}\text { NATURE/ } \\
\text { GEOGRAPHY }\end{array}$ & $\begin{array}{c}\text { TRANSPORT/ } \\
\text { ACCOMMODATION }\end{array}$ & $\begin{array}{c}\text { PRACTICAL INFO/ } \\
\text { OPEN SOCIETY IMAGE }\end{array}$ \\
\hline green nature & railway station & accessible tourism \\
\hline natural health & small tourist train & consular mission \\
\hline karstic area & camper van & Slovenian language \\
\hline Slovenian coast & tree house & safe country \\
\hline ecological matter & motor home & lesbian community \\
\hline Slovenian capital & drinking water & direct contact \\
\hline
\end{tabular}

Table 3. Frequent multi-word terms in the Slovenian Corpus

As we can see from Table 3 (above), the main topics of the Slovenian Corpus are nature and landscapes with the word green recurring also further in the corpus with multi-word terms appearing twice: smell of green nature, unspoilt nature, green country, ecological tourist, wine-growing region, and other references to Slovenian geographical features and the capital city. This strategy is in accordance with the logo, slogan and the key concepts in the featured video materials. Texts referring to natural and urban landscapes are accompanied with a lot of practical information regarding various and unusual types of accommodation, which are also evidenced in the plentiful multi-word terms that appeared twice in the corpus: glamping accommodation, unusual accommodation, 24-hour service, hotel comfort, royal comfort, world-class comfort, youth hostel, etc. As we can see from Image 2 (above), there is a separate internal link in the Plan your trip section for the LGBT community, promoting Slovenian openness to diverse types of lifestyle, which is also evidenced in the term lesbian community being in the top 18 combinations. This is the only website in our sample that offered detailed, welcoming information to the community of LGBT travellers.

\subsection{Keywords, terms and concepts in the North Macedonian website}

Although the main visual and spatial modes used in the websites are similar, North Macedonia website applied a somewhat different strategy in terms of promoting more traditional cultural values and historical background of the country including a detailed presentation of its multi-cultural heritage in the About section under the subheading Did you know!?

As we can see in Image 4 (above), this strategy is followed in the logo which incorporates cultural elements, evoking the country's flag symbolising the sun. The slogan Macedonia Timeless in special decorative font is centrally located above the image of ancient housing on the lake, which can be associated with something authentic, traditional, also nature-bound, as well as eternal. The one-minute short promotional 


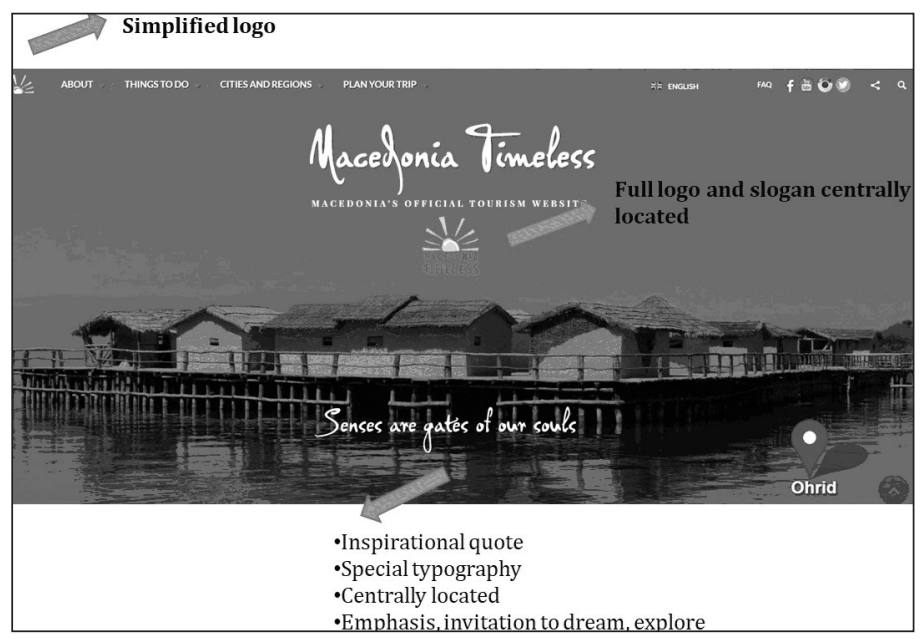

Image 4. North Macedonia's tourism website homepage

video clip on Macedonia follows this thread and is a classic form of storytelling (images of a father telling a visual bedtime story to his daughter with emotional gestures from the little girl). The story unfolds with traditional folkdance scenes, narrow cobbled streets of an old town, traditional costumes, mythological references from the past, references to a regionally famous traditional folk song 'Biljana platno beleše' (The song is about a girl who washed the linen in Lake Ohrid). The video clip ends with the slogan Macedonia Timeless. The video succeeded in a very effective and memorable use of a visual narrative, promoting authentic cultural identity of North Macedonia heritage.

Regarding the textual corpus, there were 529 multi-word terms recognized by the Sketch Engine tool, including 461 combinations that appeared only once in the authentic corpus and not appearing in the referential corpus (e.g. interesting tourist destination, Byzantine court, Byzantine family, cultural heritage of special importance, sandy layer, etc.).

\begin{tabular}{|l|c|c|c|}
\hline Multi-word term & Score & Freq & Ref_freq \\
\hline 20th century & 70.75 & 9 & 1912 \\
\hline immediate vicinity & 444.17 & 8 & 67 \\
\hline second half & 54.87 & 7 & 1919 \\
\hline 16th century & 167.84 & 6 & 367 \\
\hline large number & 33.48 & 6 & 2793 \\
\hline
\end{tabular}


Dragana Vuković Vojnović

\begin{tabular}{|l|c|c|c|}
\hline 6th century & 263.89 & 5 & 83 \\
\hline ground floor & 106.49 & 5 & 557 \\
\hline original appearance & 268.1 & 4 & 15 \\
\hline missionary work & 238.88 & 4 & 46 \\
\hline 19th century & 36.76 & 4 & 1605 \\
\hline military school & 202.26 & 3 & 14 \\
\hline missionary activity & 201.31 & 3 & 15 \\
\hline great damage & 199.06 & 3 & 18 \\
\hline cultural development & 168.63 & 3 & 64 \\
\hline main entrance & 105.42 & 3 & 245 \\
\hline west side & 83.01 & 3 & 375 \\
\hline foreign policy & 27.7 & 3 & 1,598 \\
\hline first time & 2.86 & 3 & 17,558 \\
\hline
\end{tabular}

Table 4. Macedonian Corpus - multi-word terms that appeared three or more times

As seen in Table 4 (above), there were 18 multi-word terms that appeared three or more times in the analysed authentic corpus with clear references to Macedonian history and tradition. Some of the collocations had a high keyness score (e.g. 444.17 for immediate vicinity, 268.1 for original appearance, 238.88 for missionary work) which categorizes them as multi-word terms for this particular corpus, which means they are part of specialized terminology. On the other hand, collocation first time with three appearances in the specialized corpus has a much lower score (2.68), which means it is not a specialized term. This is further proven by its high frequency in the general reference corpus where it appeared 17,558 times.

\begin{tabular}{|c|c|c|}
\hline TIME REFERENCE & PRACTICAL INFO & CULTURAL REFERENCE \\
\hline $20^{\text {th }}$ century & immediate vicinity & original appearance \\
\hline $16^{\text {th }}$ century & large number & missionary work \\
\hline second half & ground floor & military school \\
\hline $6^{\text {th }}$ century & main entrance & missionary activity \\
\hline $19^{\text {th }}$ century & west side & great damage \\
\hline first time & & cultural development \\
\hline & & foreign policy \\
\hline
\end{tabular}

Table 5. Frequent multi-word terms in the Macedonian Corpus 
If we refer to the Table 5 (above), we can see that the selected word combinations corroborate the overall trend recognized in the About section texts which recount a detailed history of North Macedonia throughout several centuries with many references to some specific cultural heritage still evident in North Macedonia. This is also followed with other terms appearing two times in the corpus, such as Slavic alphabet, Serbian king, Moravian mission, epoch-making missionary work, monastery church, marble plaque, Turkish translation, Slavic language, Byzantine period.

\subsection{Keywords, terms and concepts in the Serbian website}

Regarding the Serbian tourism campaign for international tourists, we can clearly observe that it is somewhere in between the two campaigns that we have already analysed in this article. On the one hand, it uses a more youthful, modern approach in the creation of the logo and the slogans, as well as in the video clips. On the other hand, in the textual segment it promotes tradition, historical and cultural heritage values. It is also interesting to observe that the tourism promotional campaign has been changing more rapidly and that there are three slogans that coexist on various social media sites: Serbia - One Journey, Million Impressions, Serbia - Follow your Heart, which successfully relates to the typography of the logo, and Serbia-the Place to Be: See Serbia, which is the latest campaign and the one analyzed here.

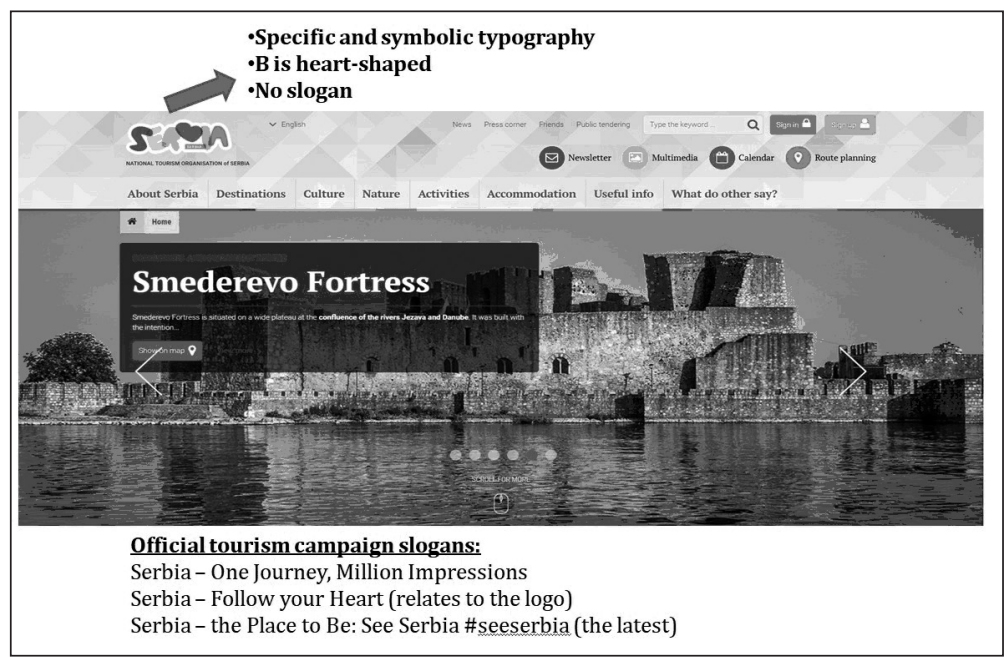

Image 5. Serbia's tourism website homepage

As we can see from Image 5 (above), the Serbian logo is colourful with modern typography and the letter B is heart-shaped, which could have a special appeal for 
younger visitors. The slogan is not included in the first screen of the homepage but it is present in a series of video clips entitled Serbia - the Place to Be: See Serbia. The main video document for the English-speaking tourists is a longer five-minute version with a narrator presenting everything that we see in the video which is about natural, historic and cultural attractions featuring places and people across Serbia. For the purpose of this article, we investigated a short, one-minute version of the video clip Serbia - the Place to Be: Culture which corresponds more closely to the other two videos previously mentioned. In this video, there are images of rural and urban landscapes, modern and traditional architecture, people of diverse cultural backgrounds, references to ancient and religious heritage, classic and modern art all accompanied by instrumental classical-like, refreshing music. The slogan and the logo appear at the beginning and the end of the video with the heart-shaped letter B beating as a heart both visually and with the sound of the heartbeat.

\begin{tabular}{|l|c|c|c|}
\hline Multi-word term & Score & Freq & Ref_freq \\
\hline snow cover & 576.58 & 6 & 38 \\
\hline south-western Serbia & 445.84 & 4 & 0 \\
\hline recorded temperature & 445.84 & 4 & 0 \\
\hline mean monthly temperature & 442.3 & 4 & 2 \\
\hline monthly temperature & 438.82 & 4 & 4 \\
\hline annual number & 406.79 & 4 & 23 \\
\hline annual rainfall & 390.06 & 4 & 34 \\
\hline air temperature & 311.12 & 4 & 103 \\
\hline small coat & 334.63 & 3 & 0 \\
\hline serbian uprising & 334.63 & 3 & 0 \\
\hline serbian poet & 333.3 & 3 & 1 \\
\hline serbian language & 331.97 & 3 & 2 \\
\hline turkish rule & 325.2 & 3 & 7 \\
\hline year round & 59.54 & 3 & 1098 \\
\hline first day & 24.84 & 3 & 2964 \\
\hline
\end{tabular}

Table 6. Frequent multi-word terms in the Serbian Corpus

As regards the textual corpus, 410 multi-word terms were listed by the Sketch Engine tool, with 153 combinations that appeared only once in the authentic corpus without appearing in the referential corpus (e.g. multi-confessional society, common Serbian slava, centuries-long position, South Slavic language family, first Serbian 
ruler, Serbian soil, Second Serbian Uprising). It was surprising to discover that in the Serbian Corpus, there were 173 multi-word terms which also appear in the referential corpus from twice in the general referential corpus (e.g. academic realism, psychological story) to up to 6,226 times (e.g. next year). A closer look at the list in Table 6 showed an unusual combination small coat, but concordance view showed that it was a part of the expression a small coat of arms (Image 6).

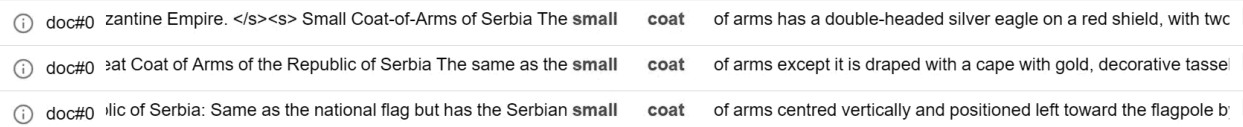

Image 6. Serbian Corpus - small coat of arms concordance

\begin{tabular}{|l|l|l|}
\hline $\begin{array}{l}\text { GEOGRAPHICAL } \\
\text { REFERENCE }\end{array}$ & TIME REFERENCE & CULTURAL REFERENCE \\
\hline snow cover & year round & Serbian uprising \\
\hline south-western Serbia & first day & Serbian poet \\
\hline mean monthly temperature & & Serbian language \\
\hline monthly temperature & & \\
\hline small coat & & \\
\hline mean annual air & & \\
\hline
\end{tabular}

Table 7. Frequent multi-word terms in the Serbian Corpus

Furthermore, there were 15 multi-word terms that appeared three or more times in the analysed authentic corpus with those that clearly belong to the general corpus: first day (2,944 times in the referential corpus), year round (1,098 times in the general corpus) and some more specific ones but still with the high frequency in the general reference corpus (e.g. air temperature, annual rainfall, annual number, snow cover). In Table 7 (above), it is evident that the topics recognised in the Serbian Corpus refer to a detailed geographical description of the country in terms of physical and social geographical features, followed by historical and religious references, as well as the descriptions of key cultural concepts and traditional customs. This approach is not completely aligned with the visual representations in the videos, so it could be argued that their specific strategy was to address different types of visitors to Serbia.

\subsection{Final remarks}

To conclude the discussion section, it was clearly observed that the overall spatial and visual organisation of the websites was similar in all three cases. Slovenia, 
with its campaign I Feel Slovenia, adopted a more up-to-date, direct approach to its potential visitors without burdening the site with historical data, but still managing to present its cultural heritage and values. It could be said that the public image they created was of an open, friendly, accessible country which invites you to explore it in any way you desire.

With the campaign Macedonia Timeless, North Macedonia accepted a completely different approach and positioned itself as a country with a long-standing tradition, influenced by various cultures incorporated even today in the society, rich in natural and cultural heritage, where old and new concepts are intertwined.

Finally, the latest tourism campaign of Serbia entitled Serbia - the Place to Be: See Serbia is somewhere in between, with the visual representations being more about a thriving, modern society where cultural and natural heritage is considered valuable, whereas the textual corpus is more factual describing the country with detailed geographical and historical references.

\section{Implications and conclusion}

As English became a global language of communication in diverse academic and professional contexts (Hutchinson and Waters 1987), language teaching methodology along with the course content of English for specific purposes have both developed with this in mind. The teachers of languages for specific purposes are often faced with the challenge of developing lessons with a specific content, focussing on the particular needs of their students and trying to design class activities according to the proposed learning outcomes (Dudley-Evans and St John 1998). Following the development of technology and the role it plays in modern communication, innumerable linguists have adopted multidisciplinary approaches, especially in discourse and communication studies in the context of languages for specific purposes.

In spite of the fact that language of tourism is sometimes full of clichés and typical expressions, this stereotyping is rather expected in promotional texts since they very often promote cultural identity in a very positive light. In pedagogical terms, it is important for students and professionals in the tourism and hospitality sector to become aware of the nature and typical properties of English for Tourism. They can critically analyze the symbolic and functional characteristics of the language of tourism and learn how to successfully combine different modes of communication in the context of their profession. For example, 'storytelling' technique in the context of tourism promotion is a very powerful tool, which now, with modern social media, can be done visually and not only verbally. Short promotional films (with or without text) can be used as visual stimuli for students who can ultimately imagine and tell their version of the story inspired by the images. Authentic images and videos can be used 
for eliciting keywords and terminology, and comparing them with the accompanying texts. Furthermore, pedagogical activities could include matching short promotional films with the slogans and promotional written texts, so that students can explore the language further in terms of its characteristics, vocabulary or collocations that are often used in such descriptions. Encouraging innovation and creativity through the use of wordplay or metaphor can motivate students to actively develop their skills and trigger discussion on cultural values and identity in the context of tourism promotion topic. Finally, the use of new technological ways of communication provides an innovative framework of realistic and relevant situations for ESP students and teachers and develops their creativity.

Multimodal analysis of websites and visuals accompanied with the corpus analysis of texts can be helpful in identifying keywords and terminology behind specialized discourse, in this case tourism discourse. If these methods are combined with the discussion about specific features of the language of tourism, especially in terms of its vocabulary, powerful pedagogical tools, activities and material can be developed. This sort of multidisciplinary approach can also find its place in applied linguistics studies, LSP learning pedagogy, tourism marketing and other multidisciplinary studies.

\section{References}

Bhatia, V. K. (1993). Analyzing Genre: Language Use in Professional Settings. London: Longman.

Bhatia, V. K. (2002). Applied Genre Analysis: A Multi-perspective Model. Iberica, 4, 3-19.

Bruner, E. M. (2005). Culture on Tour: Ethnographies of Travel. Chicago: University of Chicago Press.

Bruner, E. M. (2005a). The Role of Narrative in Tourism. Paper presented at On Voyage: New Directions in Tourism Theory, October 7-8, Berkeley Conference. (13 May 2019) <www.nyu.edu/classes/bkg/tourist/narrative.doc>.

Brown, G. and G. Yule (1983). Discourse Analysis. Cambridge, New York: Cambridge University Press.

Culler, J. (1990). The Semiotics of Tourism: Framing the Sign: Criticism and Its Institutions. University of Oklahoma Press.

Dann, G. M. S. (1996). The Language of Tourism: a Sociolinguistic Perspective. Wallingford: CAB International. 
Dudley-Evans, T. and M. J. St John (1998). Developments in ESP: A Multi-disciplinary Approach. Cambridge: Cambridge University Press.

Hutchinson, T. and A. Waters (1987). English for Specific Purposes: A Learningcentred Approach. Cambridge: Cambridge University Press.

Jaworski, A. and A. Pritchard (eds.) (2005). Discourse, Communication and Tourism. Clevedon, Buffalo, Toronto: Channel View Publications.

Jewitt, C. (2004). Multimodality and New Communication Technologies. In: P. Le Vine and R. Scollon (eds.), Discourse and Technology: Multimodal Discourse Analysis, Washington, D.C.: Georgetown University Press, 184-195.

Kress, G. (1997). Visual and Verbal Modes of Representation in Electronically Mediated Communication - the Potentials of New Forms of Texts. In: I. Snyder (ed.), Page to Screen: Taking Literacy into the Electronic Era, London: Routledge, 53-79.

Kress, G. (2010). Multimodality: A Social Semiotic Approach to Contemporary Communication. Oxon, England: Routledge.

Pauwels, L. (2012). A Multimodal Framework for Analyzing Websites as Cultural Expressions. Journal of Computer-Mediated Communication, 17, 247-265.

Scollon, R. and P. Le Vine (2004). Multimodal Discourse Analysis as the Confluence of Discourse and Technology. In: P. Le Vine and R. Scollon (eds.), Discourse and Technology: Multimodal Discourse Analysis, Washington, D.C.: Georgetown University Press, 1-6.

Swales, J. M. (1990). Genre Analysis: English in Academic and Research Settings. Cambridge: Cambridge University Press.

Thurlow, C. and A. Jaworski (2011). Tourism Discourse: Languages and Banal Globalization. Applied Linguistics Review, 2, 285-312.

Van Leeuwen, T. (2004). Ten Reasons Why Linguists Should Pay Attention to Visual Communication. In: P. Le Vine and R. Scollon (eds.), Discourse and Technology: Multimodal Discourse Analysis, Washington, D.C.: Georgetown University Press, 7-19.

\section{Online sources}

The Republic of Macedonia Agency for Promotion and Support of Tourism. (10 January 2019) <http://tourismmacedonia.gov.mk $>$.

North Macedonia Timeless. (10 January 2019) <https://macedonia-timeless.com/>.

I Feel Slovenia. (10 January 2019) <https://www.slovenia.info/en>.

National Tourism Organization of Serbia. (10 January 2019) <http://www.serbia. travel/home.779.html>. 
Romania. Natural and Cultural. (10 July 2019) $<$ http://romaniatourism.com/ . Greece. All Time Classic. (10 July 2019) <http://www.visitgreece.gr/ >.

CNN Travel. Business Traveller. 20 most memorable destination slogans. (20 May 2019) <http://edition.cnn.com/2015/06/01/travel/gallery/20-most-memorabledestination-slogans $/>$.

Tourist Versus Traveller. 105 Tourism Slogans around the World. (5 August 2019) $<$ https://touristvstraveller.wordpress.com/2012/11/20/105-tourism-slogansfrom-around-the-world-wtm12/>.

United Nations World Tourism Organization. (10 July 2018) <http://www.unwto.org>. 